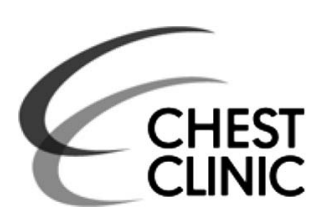

${ }^{1}$ Department of Cardiology, The First Hospital of

Qinhuangdao, Qinhuangdao, Hebei Province, China

${ }^{2}$ Department of Clinical Laboratory, The Third Hospital of Qinhuangdao,

Qinhuangdao, Hebei Province, China

\section{Correspondence to}

Dr Qiang Sun, Department of Cardiology, The First Hospital of Qinhuangdao, No. 258, Wenhua Road, Qinhuangdao, Hebei Province 066000, China; hospitalno1@126.com

Received 9 March 2016 Revised 24 March 2016 Accepted 29 March 2016 Published Online First 21 April 2016

\section{SLinked}

- http://dx.doi.org/10.1136/ thoraxjnl-2016-208497

CrossMark

To cite: Sun $Q$, Wang B-Y, Wang Q-S, et al. Thorax 2016;71:774-775.

\title{
Bochdalek hernia as unusual cause of massive hydrothorax in a 50-year-old man
}

\author{
Qiang Sun, ${ }^{1}$ Bao-Ying Wang, ${ }^{2}$ Qing-Sheng Wang, ${ }^{1}$ Qiang $\operatorname{Tan}^{1}$
}

A 50-year-old man was urgently admitted to our department with acute dyspnoea and upper abdominal pain for $4 \mathrm{~h}$. He had no history of any previous thoracoabdominal trauma or surgery. On physical examination, auscultation revealed diminished breath sound with dullness to percussion over the left hemithorax. There was marked abdominal tenderness on the left side, but no guarding or rebound tenderness. The leucocyte count revealed a marked leucocytosis of $23.87 \times 10^{9} / \mathrm{L}$ with a mildly elevated neutrophilic differential (77.1\%). Other laboratory examination was unremarkable. Chest CT revealed the colon with air-fluid level (figure 1A, arrowheads) in the left hemithorax. Massive pleural effusion (figure $1 \mathrm{~B}$ arrows) complicated with atelectasis (figure $1 \mathrm{~B}$ arrow heads) was found on the axial CT. The sagittal image of chest CT scan illustrated the colon into the left thoracic cavity through diaphragmatic defect (figure 1C, arrow heads). A thoracolaparotomy was performed and showed a Bochdalek hernia containing the
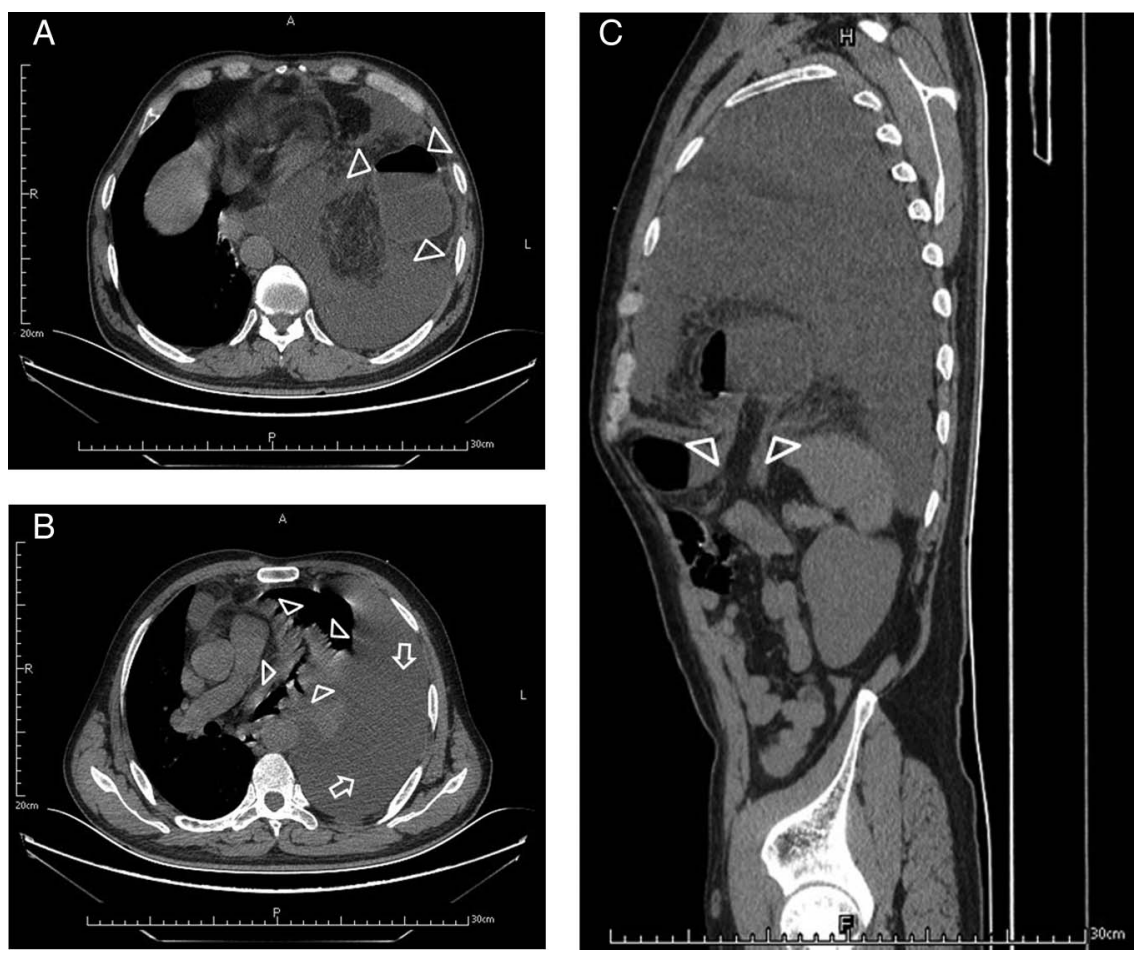

Figure 1 (A) Chest CT showed the colon with air-fluid level (arrowheads) in the left thoracic cavity. (B) Chest CT illustrated a massive left-sided pleural effusion (arrows) with atelectasis (arrowheads). (C) The sagittal images of chest CT scan revealed the large Bochdalek gap (arrowheads) with intrathoracic herniation of the transverse colon. colon and omentum. The herniated colon and omentum were released back into his abdomen and the diaphragmatic defect was repaired. After surgery, plain chest film showed a fully expanded left lung. The patient had an uneventful postoperative recovery and remained free of symptoms at 1-month follow-up.

Bochdalek hernia is one of the most common types of congenital diaphragmatic hernia, which is mostly diagnosed in children. However, the true prevalence of Bochdalek hernia remains unknown, ranging from $0.17 \%$ to $6 \% .{ }^{1} \mathrm{Up}$ to now, only around 100 cases of occult asymptomatic Bochdalek hernia in adults have been reported in the published literature. ${ }^{2}$ The symptomatic case owing to Bochdalek hernia with colon strangulation is an extremely rare condition. ${ }^{3}$ The condition may be life-threatening if there is no timely and effective treatment. As in this case, early diagnosis and surgical intervention can decrease morbidity and mortality. 
Contributors QS: the main contributor of this article. B-YW and QT: thoughtful comments on the manuscript.

Competing interests None declared.

Patient consent Obtained.

Provenance and peer review Not commissioned; externally peer reviewed.

\section{REFERENCES}

1 Schumpelick V, Steinau G, Schlüper I, et al. Surgical embryology and anatomy of the diaphragm with surgical applications. Surg Clin North Am 2000;80:213-39.

2 Mullins ME, Stein J, Saini SS, et al. Prevalence of incidental Bochdalek's hernia in a large adult population. AJR Am J Roentgenol 2001;177:363-6.

3 Kocakusak A, Arikan S, Senturk O. Bochdalek's hernia in an adult with colon necrosis. Hernia 2005;9:284-7. 